\title{
Verder Scientific
}

\section{на рынке лабораторного оборудования}

\section{Рассказывает инженер по продажам компании Verder Scientific Скотт Рееве}

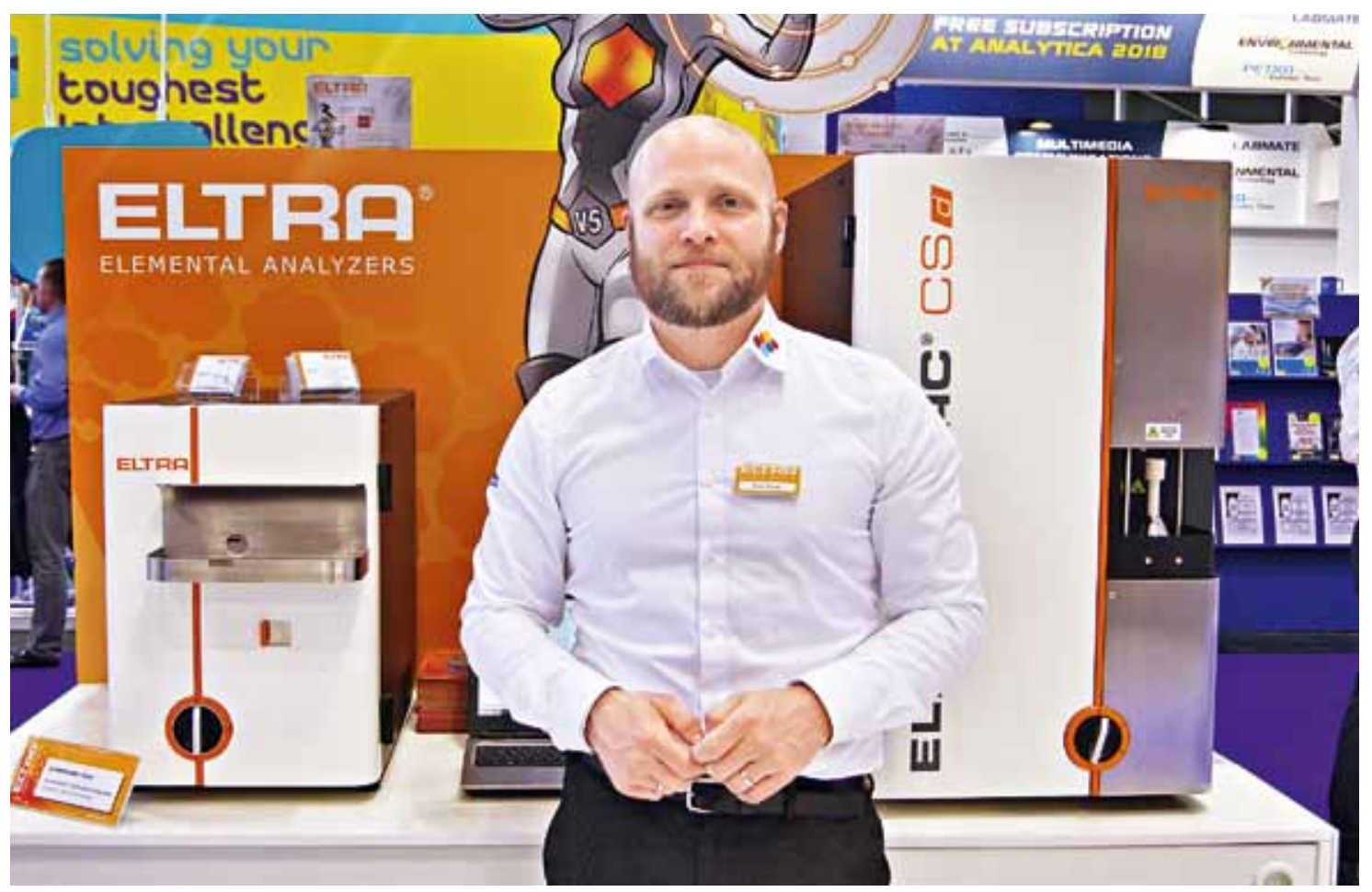

Компания Verder Scientific, являющаяся подразделением холдинга Verder Group, специализируется в области высокотехнологичного научного оборудования для контроля качества, исследований и разработок твердых материалов. Численность персонала компаний, объединенных брендом Verder Scientific, составляет около 800 человек, которые занимаются разработкой и производством лабораторного оборудования для пробоподготовки для материаловедения и металлографии, подготовки проб измельчением и гомогенизацией, термической обработки (физические испытания материалов), определения размеров и формы частиц сыпучих материалов, измерения твердости, а также элементного состава. Оборудование выпускается фирмами ATM, Carbolite, Carbolite Gero, ELTRA, Retsch, Retsch Technology и QNESS.

На выставке analytica 2018 Verder Scientific показала целый ряд новинок, представляющих большой интерес, в том числе и для российских потребителей. О некоторых самых востребованных экспонатах рассказал инженер по продажам компании Скотт Рееве.

Представьте, пожалуйста, компанию ELTRA.

Компания ELTRA - один из лидирующих производителей элементных анализаторов для быстрого и точного анализа твердых и жидких материалов, в том числе выполняемых под заказ. Свой первый анализатор углерода и серы с печью сопротивления специалисты компании разработали еще в 1981 году. Сегодня компания вышла на новые рынки и расширила круг потребителей и заказчиков, благодаря производству анализаторов кислорода, азота и водорода. 


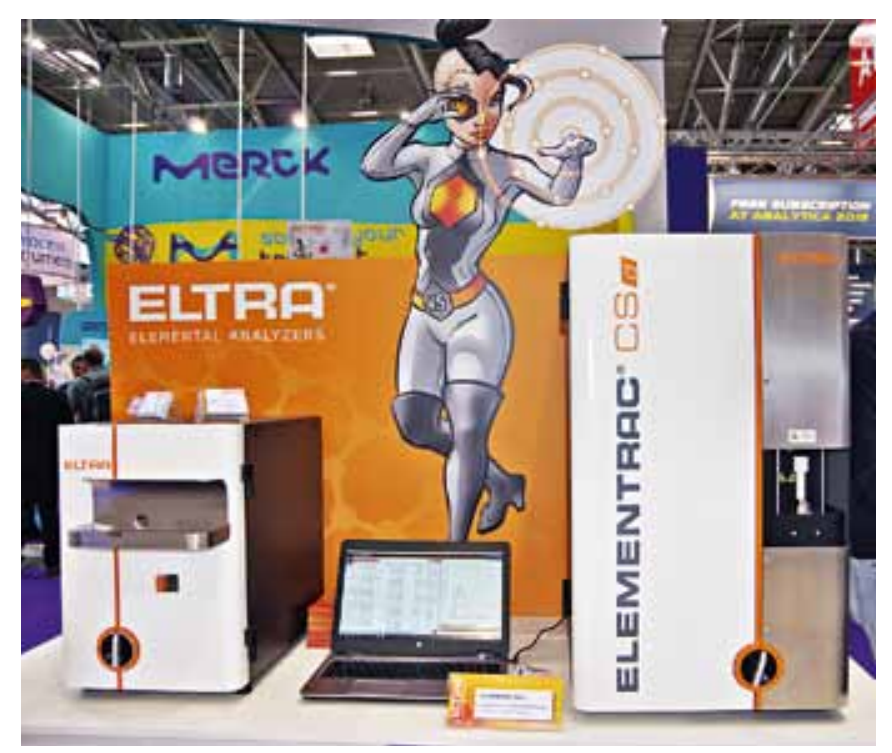

Какую новую продукцию вы предлагаете в рамках выставки?

Это в первую очередь новый анализатор ELEMENTRAC CS-i, который был разработан для выполнения точного и безопасного анализа неорганических материалов на содержание углерода и серы.

Анализатор оснащен мощной индукционной печью для сжигания пробы. Он может быть снабжен четырьмя инфракрасными кюветами, что позволяет выполнять на одном анализаторе измерения как высоких, так и низких концентраций. Вместе с прибором поставляется новое программное обеспечение ELEMENTS, в которое интегрированы функции статистики, группировки результатов, создания отчетов, диагностики анализаторов серии ELEMENTRAC и др.

\section{В чем конкурентные преимущества этого оборудова- ния?}

Во-первых, одновременный анализ углерода и серы при минимальной пробоподготовке. Во-вторых, возможность выполнять анализ различных неорганических материалов. С помощью программного обеспечения можно управлять мощностью индукционной печи, выполняя точные анализы материалов с низкой температурой плавления. Автоматическая система чистки печи с пылесосом позволяет улучшить стабильность и точность результатов анализа, а оптимизированная каталитическая печь с контролем температуры обеспечивает точное определение углерода. Оборудование надежной конструкции требует минимального обслуживания и предназначено для работы как на производстве, так и в лаборатории.

\section{В каких сегментах рынка вы работаете?}

Наше оборудование стало своего рода стандартом для таких сфер, как металлургия, автомобилестроение, добыча, разработки, исследования, аэрокосмическая отрасль и др.

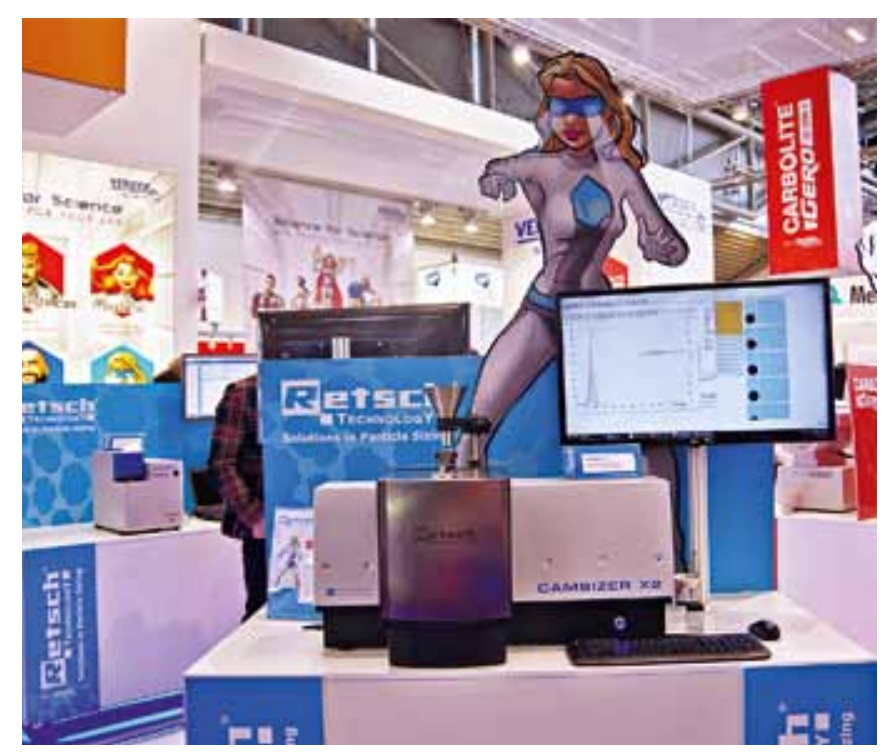

Кроме того, относительно новыми направлениями для нас являются лаборатории химического анализа, которые занимаются исследованием новых веществ, таких как керамика или каких-либо сочетаний химических соединений, состав которых до конца не изучен.

Следующую новинку представила компания Retsch, которая получила мировую известность благодаря своему оборудованию для пробоподготовки.

\section{Расскажите немного о компании Retsch.}

Начнем с того, что приборы бренда Retsch - непременные атрибуты пробоподготовки для лабораторных анализов. Их отличает надежность, точность и долговечность. Компания обладает более чем 90-летним опытом работы и является лидером в области производства оборудования для измельчения и гомогенизации проб материалов для лабораторных анализов, а также определения размеров частиц твердых веществ.

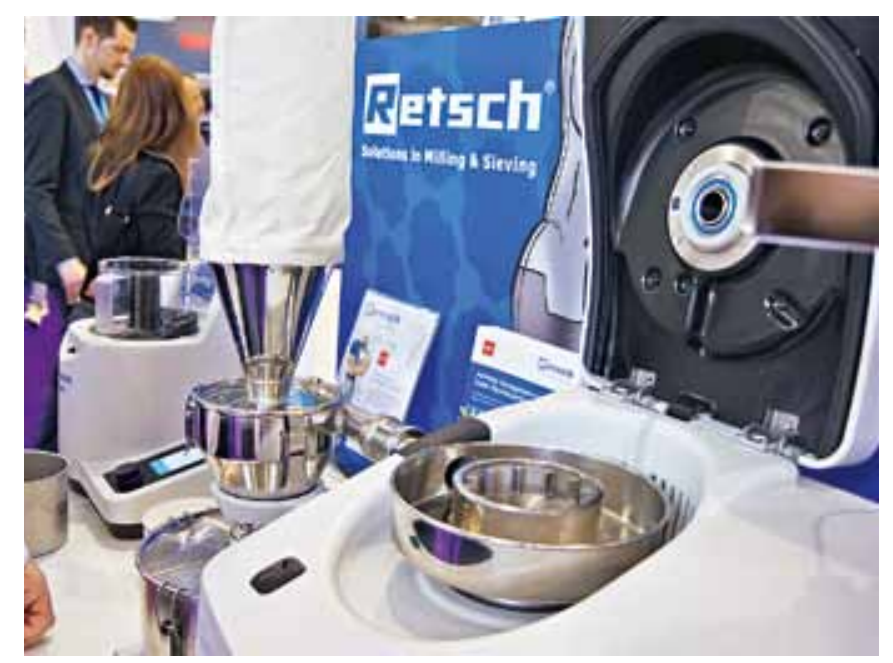


Какую из новинок вы хотели бы представить в первую очередь?

Это высокоскоростная ультрацентробежная мельница ZM 200 с высокой производительностью. Она используется для быстрого измельчения мягких, средне-твердых и волокнистых материалов. В этой мельнице реализован двухступенчатый процесс измельчения, что гарантирует бережное измельчение образцов за короткое время. Имеется полный набор дополнительных приспособлений, таких как ситовые вставки, роторы и системы сбора проб.

\section{Какие особенности данного обо- рудования вы хотели бы отме- тить?}

Это привод с оптимально подобранным конвертером частоты и трехфазным двигателем, бережная и быстрая обработка материала, широкий диапазон задания скорости. В мельнице использована запатентованная кассетная система для полного извлечения материала и легкой чистки. Корпус имеет автоматическое запирание крышки размольной камеры. Мельница оснащена дисплеем и однокнопочным управлением для удобного задания параметров процесса.

Также мы представляем щековую дробилку, разделители и просеивающие системы.

\section{Какие системы используются в аналитической химии?}

Разнообразные. Как правило, образцы измельчаются до состояния порошка. Кроме того, возможно измельчение материала не до порошкообразной формы, а дробление на мелкие кусочки. Всё зависит от цели: если образец будет использоваться для химического анализа, то не важно, в какой форме он будет - порошок или гранулы. Мы можем с успехом подвергнуть анализу и то и другое. Если необходимо получить раствор, тогда порошок будет наиболее правильным решением.

\section{Какие продукты пользуются наибольшим спросом?}

я бы сказал, что наибольшей популярностью пользуются щековые дробилки, далее идут раскалывающие машины. Также очень популярны просеивающие машины. Одну из них мы можем посмотреть на стенде.

\section{А что касается прободелителей?}

Делители проб тоже интересная позиция. Их применяют, если необходимо подать одинаковое количество образца в разные воронки. Они не так хорошо продаются, тем не менее являются важной частью продуктовой линейки компании. Очевидно, что только представительный образец, который точно отражает свойства начального материала, может дать значимые результаты анализа. Наши ротационные прободелители гарантируют представительность образца и, соответственно, воспроизводимость результатов анализа.

Представленный на выставке прободелитель РТ 100 выполняет свои функции настолько точно, что по составу каждая порция образца полностью соответствует первоначальной партии материала. Подача материала и процесс деления происходят автоматически, без перерывов и потери материала. Прободелитель имеет модульную конструкцию и может быть скомпонован под индивидуальные требования заказчика. Мы также предлагаем автоматическое устройство подачи материала и широкий выбор различных делительных головок, приемных сосудов и дополнительных принадлежностей.

\section{Каковы его преимущества по сравнению с продукцией конкурентов?}

Это высокая точность деления, модульная конструкция, автоматическая подача материала при помощи синхронизированного вибрационного питателя, система быстрого крепления приемных емкостей. Также отмечу возможность поддержания постоянной скорости вращения делительной головки для максимальной точности деления, а также большой набор дополнительных приспособлений, включая различные делительные головки, устройства сбора и подачи пробы.

\section{Спасибо за интересный рассказ.}

С.С.Рееве беседовала О.А.Лаврентьева 